tific work of Dr Arthur Jensen and its pertinence to the award of a fellowship to him". Gould called the motion "a somewhat abated formulation but probably the best we can do". Dr William Carey, Executive Officer of the AAAS, argued against it on the ground that if it were adopted he saw no end to the issue. That incensed one member, Dr James Silverberg, an anthropologist, who said "the reason we are spending so much time on this is that we left Denver [the location of the last annual meeting] with egg all over our faces". Silverberg condemned the earlier general motion as "a totally hyprocritical statement. We have evidence that we knew what we were doing" and threatened to resign his own fellowship if the motion to reinvestigate Jensen did not pass. The motion failed by 25 votes to 10 , a larger margin than the original vote last year to elect Jensen ( 28 votes to 24 ).

After the meeting, Gould expressed no surprise that the vote had gone the way it did. "The typical council member is an organisation man" said Gould. Gifford, on the other hand, was more disappointed. Humphreys had supported the investigation, retaining his belief in Jensen, and it had seemed to Gifford at that point as if the vote might go for the inquiry. Gifford is now believed to be planning to set up an ad hoc investigation of Jensen's work outside the auspices of the AAAS. He also believes the seeds of another Jensen affair may have already been sown with the election to fellowship this year of Dr Robert W. Fogel, author of the book, The Economics of American Negro Slavery. The book argues that the Negro slave was better off and happier than is usually thought. "Fogel is a friend of mine" said Gifford "but this book doesn't represent his best work".

Robert Walgate

\section{Special treatment for Cuba and Mongolia}

CuBA and Mongolia are to receive preferential treatment as 'lessdeveloped' countries, under the Comecon plans for scientific and technical cooperation. This was announced by the Cuban Deputy Premier, Belarmino Castella Mas, in his opening speech at the eighteenth session of the Committee for Scientific and Technical Cooperation; the first meeting of this committee to be held in Cuba.

Comecon cooperation in science and technology, as in all other branches of the economy, is officially governed by the 'Complex Programme of Further Intensification and Perfection of the Cooperation and the Development of Socialist Economic Integration among the Comecon countries' of 1971.
This laid down long-term objectives (up to 1990), including the formation of international scientific and technical associations, joint laboratories, coordination centres, scientific and technical councils and study groups.

The programme, however, seems to have proved too grandiose in practice so the January 1976 meeting of the Committee on Scientific and Technical Cooperation stated that for the present, scientific cooperation will be largely devoted to research projects "which cannot be solved by individual countries".

The recent session of the Committee had as the main item on its agenda the accelerated development of science and technology in Cuba. Comecon planning policy tends to follow current Soviet doctrine; hence the current emphasis is on practical applications rather than basic research. Development programmes will include the increased use of modern technology in the cultivation and processing of sugar cane, 'agro-industrial' development of citrus fruit production, the use of nuclear energy (a power station is to be built in Cuba by the Soviet Union), solar energy, and the development of the electrical power system. Plans to increase Cuban nickel and cobalt production to 130,000 tonnes per year (almost a quarter of the total world nickel output) have already been under way for a year.

Details of the financing of these projects are not available. Rather remarkably there is no central Come-

\section{Denmark follows UK on DNA guidelines}

DENMARK is preparing guidelines for research involving genetic engineering. At the end of last year, the Danish Parliament offered broad approval to the recommendations laid out in a report of the 'Registration Committee for Genetic Engineering' and assigned to the Committee the task of working out preliminary guidelines for experiments involving recombinant DNA.

The Committee was set up by the Danish Research Councils in July 1976 on lines similar to those of committees in other countries. Its task was to formulate proposals for the Commission for Genetic Engineering, a permanent organisation to control genetic engineering in Denmark, and then to function as the Commission pending its establishment. The Committee is made up of representatives from the National Health Service, the Agency for Environmental Protection, the pharmaceutical industry and the Ministry of the Interior.

To find out where genetic engineer- con fund for financing joint research projects, and all cooperation projects have to be based on ad hoc financial agreements between the member countries concerned. It is noteworthy, however, that while Eastern Europe has a considerable beet sugar industry, there seems to be an upper limit to further expansion-increased use of fertiliser providing larger gross tonnage of beets but no larger yield of sugar.

Investment in the Cuban sugar industry, whether or not repaid directly in kind, is likely to benefit the flagging food industry of Eastern Europe. And the development of Cuban nickel will provide a much-needed component of high-quality steels and high-strength nonferrous alloys.

To date, Cuba's contribution to Comecon has consisted largely in hosting meetings of the Executive Council and various committees, provision of a site for a satellite-tracking base, and the export of certain commodities (some of which, like cigars, are considered by the senior partners as "inferinr"). Likewise, Mongolia's main contribution has been in geological surveys which will ultimately provide raw materials for the bloc.

The new "preferential treatment" of Cuba and Mongolia while undoubtedly beneficial to the development of their economies, still seems ultimately directed at the over-all good of Comecon in toto. The plans for the 'less developed' members clearly reflect the ultimate aim of an integrated economy.

Vera Rich

ing research is done in Denmark, the Committee inquired into 195 public and private laboratories and organisations and found that no such research has yet been done. Two laboratories, however (one of them the Carlsberg Laboratory), intend to do experiments involving genetic engineering very soon.

Many of the report's recommendations are in line with those of the UK Williams report rather than the US NIH guidelines. This suggests that the Committee has taken into account the wish of the European Science Foundation (ESF) and the European Molecular Biology Organisation (EMBO). that regulations should be equivalent, if possible, in all European countries.

As Denmark has only very limited resources for building high containment laboratories, Danish scientists will probably carry out high-risk experiments in common. European laboratories (for example, the EMBO laboratory under construction in Heidelberg). It is therefore important that they 
should be subject to the same regulations as those operating in such international laboratories. The Committee also feels that if Denmark sticks to common guidelines, it will be able to call on experts in the ESF's 'Liaison committee on recombinant DNA research'-on which it is representedfor advice with specific genetic engineering problems.

The report's recommendations aim at controlling public as well as private research and ensuring that the community has the power to regulate the use of any results from genetic engineering research which may pose hazards to the environment, animals or man. And that power, the report says, should eventually be vested in the Commission for Genetic Engineering when it is set up.

All research and production using genetic engineering will then have to be made known to the Commission and particularly hazardous procedures will not be allowed to go ahead without the Commission's approval. Laboratories will have to be approved by the Directorate of Labour Inspection, or by a public or private institution authorised by the Directorate in collaboration with the Commission. People working with genetic engineering will have to be adequately trained; accurate records will have to be kept of all experiments; accidents will have to be immediately notified to the Commission and laboratories will have to be inspected regularly.

A point which the Registration Committee suggests should be looked into further is the question of whether existing Danish law (the Epidemics Act 1915, the Working Environment Act 1975, the Environment Protection Act 1973) affords a sufficient supervisory authority to inspect laboratories or whether special legislation will be needed. Eventually, however, recommendations from the European Economic Community (EEC) will have to be taken into account on the latter point. As yet no decision has been taken on which central authority the Commission should be placed under, but the Registration Committee suggests that the National Health Service, which supervises other forms of microbiological research, might be the most suitable.

The Registration Committee's next task will be to collaborate with the National Health Service, the Directorate of Labour Inspection and the Agency of Environmental Protection to work out preliminary guidelines for registration, supervision, approval of laboratory facilities and so on. In the meantime it will keep the government and administrative authorities informed of developments abroad.

Sven Godtfredsen

\section{First Ratan results published}

THE first results of experiments with Ratan- 600 , the $600 \mathrm{~m}$ radio-telescope of the Soviet Academy of Sciences, have recently been published. The experiments are essentially exploratory and performance trials ranging from solar to extra-galactic observations.

The Ratan-600 represents a new generation of radio-telescopes. Its design parameters are impressive: information capacity $3 \times 10^{12}$ bits, limiting resolution 2 arc sec, accuracy of definition of coordinates $0.01 \mathrm{sec}^{2}$, limiting flux density 0.01 Jansky, limiting brightness temperature $0.03 \mathrm{~K}$, sky coverage $70-80 \%$ with scanning time 100 days. Ultimately it is hoped that Ratan-600 will not only provide direct observational results, but will serve as a basis for experiments estimating the intensity of gravitational waves and confirming general relativity on the basis of the bending of rays in the gravitational field of the sun. Although these sophisticated experiments lie in the future, a number of interesting results have already been obtained.

The high resolution and large collecting area of RATAN-600 permit the observation of solar "pores"-areas of limitingly weak activity which will later develop into sunspots. It also allows the radiogranules, first discovered during the transit of Mercury in 1970 to be monitored in non-eclipse conditions and for several frequencies simultaneously. A programme of joint radio and optical investigation of solar granules has been initiated and preliminary investigations obtained for their magnetic fields.

Likewise, the high resolution made it possible for RATAN-600 to receive radio-emissions from all four of the "Galilean" satellites of Jupiter, in spite of the intense radio-emission from the planet itself. These observations-in December 1976 and January 1977, gave the first results ever for Io, the closest, and Europa, the nearest, of the four. For Ganymede, Callisto and Europa, the results were consistent with thermal emission only, showing no signs of the intense radiation bands observed for Jupiter itself. For Io, however, the result was "totally unexpected"-radio-emission is several times greater than the expected thermal value. It is claimed that this implies that Io possesses a magnetic field and intense radiation bands.

RATAN-600 is aiso participating in two joint Soviet-Australian projects, on quasars and on early-type emission line stars. Signals have been received from quasar $O Q$ 172, the most remote object in the universe (red shift 3.54). Its present programme also includes observations of the galactic centre, multifrequency mapping of radiogalaxies, and the first stages of a sky survey in the centimetre and millimetre ranges, which will take 10 years to complete and should provide a radio equivalent of the Palomar sky survey.

Vera Rich

\section{Bangladesh plans nuclear research centre...}

Bangladesh Atomic Energy Commission, in its efforts to develop peaceful applications of nuclear physics and technology, has drawn up an extensive plan to establish a nuclear research complex in Bangladesh. It will comprise seventeen nuclear and allied projects. A 259-acre site twenty-five miles north of Dacca is already under development. The laboratories are to be integrated to share facilities and also to create an environment conducive to the formation of interdisciplinary teams among the scientists of the Commission.

$\mathrm{Mr}$ H. F. S. Bittencourt, Deputy Director General of the International Atomic Energy Agency, while visiting Bangladesh in connection with the inaugural ceremony of the Institutes of Nuclear Technology, Nuclear Medicine, Electronics, Irradiation and Pest Control, the National Com- puter Centre, the Institute of Space and Atmospheric Research, and other institutes, expressed his satisfaction over the plans and assured all possible help in matters of providing the Commission with a small nuclear reactor. It is expected that the first phase of the work will be completed by 1982 , but Bangladesh still needs a 10 to $20 \mathrm{MW}$ reactor, which the BAEC hopes to get as a donation from some friendly country. Bangladesh, however, is required to obtain a nuclear safeguard clearance before obtaining a nuclear reactor and it is hoped that the IAEA will extend the necessary help.

Two irradiators each of 50,000 Curies for food irradiation and medical projects are to be procured from Canada. The first one which is expected to arrive in June next, will cost about US\$6,000.

M. Kabir 